\title{
O movimento popular de saúde de Campinas- São Paulo e sua contribuição para a política local de
} saúde / The popular health movement of Campinas - São Paulo and its contribution to the local health policy

Ana Targina Rodrigues Ferraz*

Resumo: Este artigo reconstrói a trajetória do Movimento Popular de Saúde de Campinas e as principais bandeiras de luta empreendidas por este movimento ao longo dos seus trinta anos de existência. São destacadas as conquistas obtidas e que mudaram a configuração da política de saúde do município, especialmente o processo de negociação destas políticas nos espaços de participação do Conselho Municipal de Saúde, Conselhos Locais de Saúde e Conferências.

Palavras-chave: Movimentos sociais, Conselhos gestores de políticas públicas, participação.

\begin{abstract}
This article reconstructs the path of the Popular Health Movement of Campinas and the main causes fought by this movement throughout its thirty-year existence. The conquests that changed city's health policy configuration are highlighted, especially the negotiation process of these policies in the spaces for participation in the City Health Council, Local Health Councils and Conferences.
\end{abstract}

Keywords: Social movements, Public health management councils, participation.

Introdução Os anos 1990 no Brasil apresentaram na vida política do país uma tendência: a consolidação de nossas instituições democráticas e o aparecimento de experiências de participação dos cidadãos na definição de políticas públicas por meio do orçamento participativo e dos Conselhos gestores de políticas públicas.

Estes Conselhos são, hoje, uma experiência de caráter formal, com existência regulamentada em lei, e que se generalizou

\footnotetext{
Doutora em Ciências Sociais pela UNICAMP, Professora Adjunta do Departamento de Serviço Social da Universidade Federal do Espírito Santo. E-mail: anatargina@uol.com.br
} 
por todas as áreas das políticas públicas. Para a saúde, entretanto, o debate em torno da construção de outro sistema de atenção à saúde da população tem uma história que remete aos anos 50 do século passado, para a qual concorreu tanto a organização de profissionais da área quanto a organização dos usuários dos serviços de saúde. Esta história não será recontada neste artigo por não ser este o seu objetivo e por existir uma vasta literatura sobre o tema. Aqui será reconstruída a história do Movimento Popular de Saúde de Campinas-MOPS, que contou, desde o seu início, com uma forte aliança entre população e profissionais da área (médicos, enfermeiros, auxiliares de saúde).

A aliança entre movimento popular e profissionais de saúde foi a mais marcante característica da ampla mobilização nacional, amadurecida nos anos 1970 e 1980, em torno de um projeto de reforma do sistema público de saúde do país. Em Campinas, esta aliança contou com a colaboração de participantes do debate intelectual e de formuladores do projeto de reforma do sistema de saúde. Esses participantes se encontravam nos departamentos de medicina preventiva e social da Universidade Estadual de Campinas (UNICAMP) e de medicina social da Pontifícia Universidade Católica de Campinas (PUC - Campinas). Davam a este movimento um caráter peculiar no contexto nacional em decorrência da força desta aliança no município e dos avanços na construção da política municipal de saúde que ela proporcionou.

O MOPS - Campinas foi, juntamente com o movimento sindical, um dos principais representantes dos usuários no interior do conselho municipal de saúde da cidade, constituindo-se, também, uma referência para a organização dos usuários em vários dos municípios vizinhos.

Este movimento social apresenta duas características importantes. Em primeiro lugar ele possuía uma significativa inserção no movimento nacional em torno da reforma do sistema brasileiro de saúde, assentado em forte participação popular, no 
enfrentamento direto na relação com o Estado e em um arco amplo de alianças. A segunda característica é a sua permanência ao longo do tempo, a sua longevidade. Por se tratar de um movimento com mais de trinta anos ${ }^{1}$, possibilita o vislumbre de importantes mudanças apresentadas pelo mesmo e pela política de saúde ao longo do tempo.

Neste artigo será evidenciada a importância do Movimento Popular de Saúde em todo o país para a implantação da reforma do sistema brasileiro de saúde, para a construção do processo de representação dos usuários nos canais participativos instaurados e, ainda, o modo como estes têm participado da definição da política de saúde.

A análise que agora apresentamos foi realizada a partir de dados e documentos coletados durante o doutorado em ciências sociais na Universidade Estadual de Campinas, finalizado em 2005, alguns dos quais não foram incorporados à tese. Para uma avaliação das mudanças sofridas pela política municipal de saúde a partir das reivindicações de usuários e trabalhadores da saúde foram analisados, principalmente, os relatórios das Conferências Municipais de Saúde produzidos entre os anos de 1990 e 2003.

\section{MOPS - Campinas: um pouco de história}

Em 1977 surgiram em Campinas os primeiros movimentos reivindicatórios por melhorias urbanas (transporte, abastecimento de água, luz, escolas, esgoto, etc.) nas chamadas "vilas planejadas", habitações construídas pela $\mathrm{COHAB}$ na cidade para abrigar o enorme contingente de trabalhadores desempregados e migrantes que, desde o final dos anos 50 e 60 do século XX lá chegavam, atraídos e estimulados pelo seu rápido crescimento industrial, e que

\footnotetext{
Em maio de 1988, por ocasião do II Seminário "Saúde e Participação Popular", promovido pelo Mops, é lançado um documento destinado a rever a história do Movimento Popular de Saúde em Campinas de 1977 a 1987, intitulado "História do Movimento Popular de Saúde".
} 
se encontravam em situação de favelização. ${ }^{2}$ Impulsionando estas mobilizações estavam os setores progressistas da igreja católica representados pelas CEBs e lideranças vinculadas aos partidos políticos e correntes de esquerda na clandestinidade.

A partir dos anos 50 do século passado aprofunda-se o projeto de crescimento industrial via substituição de importações, alterando profundamente o perfil de nossa economia, transformando-a de agrário-exportadora em urbano-industrial. Dentro do estado de São Paulo, a cidade de Campinas pode ser considerada emblemática deste acelerado processo de transformação. Sua economia deixa de concentrar-se na produção e exportação de café e passa a receber enormes investimentos de diversos ramos industriais (eletro-eletrônico, químico e outros).

Este processo significou alteração na composição da força de trabalho, no perfil dos postos de trabalho, nas clivagens e problemas apresentados pela sociedade brasileira. A população das cidades cresce sem que o Estado invista na infra-estrutura necessária ao atendimento de suas demandas. Ao mesmo tempo, as duas grandes políticas públicas brasileiras, saúde e previdência, continuaram restritas aos trabalhadores formalmente empregados.

Em Campinas estas alterações são visíveis no acelerado crescimento populacional da cidade, na expansão industrial e na execução de políticas destinadas a estimular este crescimento e o abandono da atividade agrícola, com a disponibilização de infra-estrutura (água, estradas e rodovias, terrenos a baixo custo, etc.) para os setores industriais e o aceno com a possibilidade de expansão na oferta de empregos à massa de trabalhadores (LOPES, 1997, p. 50-60).

No final dos anos 70 do século XX a população das "vilas planejadas", cujas principais características eram exatamente a inexistência da infra-estrutura necessária ao abrigo de seus

\footnotetext{
2 Ocupavam, para fins habitacionais, terrenos públicos e privados vazios. O movimento de favelados em Campinas tem uma história particular que não será contada aqui, embora a história do movimento popular de saúde tenha fortes vínculos com_este movimento.
} 
moradores (água, luz, escolas, postos de saúde, rede de esgoto, coleta de lixo, transporte urbano coletivo, etc.), começou a organizar-se no sentido de lutar pelo atendimento de suas necessidades. Inicialmente com a realização de abaixo-assinados e a criação de comissões para apresentar a secretários e prefeito suas reivindicações.

As CEBs foram, neste momento, os espaços privilegiados para o debate da realidade e para a convocação à luta política, uma vez que as $\mathrm{SABs}^{3}$ (sociedades de amigos de bairro), as mais antigas organizações de moradores existentes no estado de São Paulo, tinham um perfil político muito diferente do perfil que começava a ser gestado nas CEBs, caracterizado pela conciliação, pelo não enfrentamento dos poderes públicos e pelas negociações particularistas.

Em fins dos anos 1970, com o crescimento das CEBs, as sociedades de amigos de bairros se tornaram espaços de disputa política entre as lideranças vinculadas ao seu antigo perfil e as novas lideranças vinculadas às CEBs.

O adensamento das lutas dentro dos bairros por saúde, educação, habitação e transporte e a ausência de respostas satisfatórias por parte dos poderes públicos para estas reivindicações propiciaram o surgimento, em 1979, de uma organização de caráter amplo, que reuniu as populações e as reivindicações de vários bairros do município de Campinas, denominada "Assembléia do Povo". Tratava-se de uma articulação realizada entre lideranças dos movimentos populares de vários bairros da cidade para discussão de seus problemas e reivindicações. Esta articulação foi o resultado da realização mensal, a partir de março de 1979,

\footnotetext{
As SABs foram entidades criadas nos 1950 e 1960, em São Paulo, como canais de vínculo e diálogo entre população e políticos, cuja principal característica era a barganha clientelista entre lideranças populares, partidos e políticos, em que se negociavam melhorias urbanas e outros benefícios para os bairros, por votos. Embora tenham, no início dos anos 1960, assumido um perfil mais independente e de enfrentamento, nos anos da ditadura, com o esvaziamento das atividades políticas de caráter populista, passaram a desenvolver um associativismo de tipo recreativo, assistencial e religioso (LOPES, 1997, p. 74).
} 
de assembléias públicas no paço municipal da cidade, em frente à sede da prefeitura, em que um abaixo-assinado com todas as reivindicações populares foi entregue ao prefeito (MOVIMENTO POPULAR DE SAÚDE DE CAMPINAS, 1987).

A "Assembléia do Povo" constitui um momento tanto de especial adensamento das organizações e lutas da população quanto de explicitação das diferenciações existentes no interior do movimento. Se por um lado sua constituição proporcionou força e visibilidade para as organizações e reivindicações populares, por outro evidenciou, ao longo da década de 1980, as divergências existentes no interior do movimento entre lideranças vinculadas à igreja católica e outras mais próximas de partidos e políticos de esquerda.

Esta aglutinação do conjunto de reivindicações das organizações populares e a realização de grandes manifestações como forma de pressão dos poderes públicos fortaleceram o movimento popular e a unificação das lutas, ao mesmo tempo em que impulsionaram a expansão de comissões e organizações em torno de lutas específicas, como saúde e habitação, por toda a cidade. Este processo se deu, em grande medida, em razão da existência de grupos temáticos no interior da Assembléia do Povo (grupo da saúde, da habitação, da regularização fundiária, da educação) e do ganho deste novo espaço de articulação e de ação para suas lideranças.

A constituição do Movimento Popular de Saúde de Campinas resultou do processo de aglutinação das Comissões Populares de Saúde existentes nos bairros, estimuladas pelas CEBs, pela aglutinação proporcionada no ambiente da Assembléia do Povo e pelo processo de reunião, pela igreja católica, das chamadas experiências de medicina comunitária espalhadas pelo Brasil, nos ENEMECs (Encontros Nacionais de Medicina Comunitária).

Estas experiências contaram com forte apoio da igreja católica e se concretizaram em duas direções. Uma vertente, de caráter mais conservador, vinculada às recomendações da 
Conferência Internacional de Saúde, promovida pela Organização Mundial de Saúde (OMS) e realizada em 1979 na cidade de AlmaAta no atual Cazaquistão (COHN; ELIAS, 1996, p. 58), e da Organização Pan-Americana de Saúde (OPAS), desenvolveu-se por meio de uma medicina simplificada, de medidas assistencialistas, com a realização de consultas médicas por profissionais voluntários e distribuição de medicamentos. Outra vertente, de caráter progressista e democrático, procurava, além de valorizar o conhecimento popular de ervas e plantas, discutir a relação saúde-doença no contexto das condições de vida da população e de uma compreensão ampla de saúde - não mais entendida como ausência de doença, mas como uma situação de bem-estar físico, emocional e social, pela qual toda a sociedade é responsável, e cuja realização é dependente das reais condições sociais e econômicas em que vive a população.

Em Campinas, são emblemáticas as lutas das populações da região Cura D'Ars, da paróquia Cura D'Ars, reunindo as comissões populares de saúde de vários bairros e reivindicando a construção de um novo centro de saúde na região. Lutas semelhantes aconteceram de modo quase simultâneo na Vila Costa e Silva, Vila Boa Vista, Jardim Campineiro, São Marcos, Santa Mônica. Esses bairros contavam com CEBs fortemente organizadas e comissões populares de saúde assessoradas por profissionais de saúde e militantes de organizações e partidos clandestinos de esquerda.

Nos anos 1980, a vertente conservadora das chamadas experiências de medicina comunitária reduz sua influência sobre as Comissões Populares de Saúde organizadas nos bairros e o ENEMEC se transforma em Movimento Popular de Saúde, denominação que passa a designar todas as organizações e experiências populares em torno da luta pela saúde. Neste momento, também se intensificam as alianças entre trabalhadores da saúde e população e se adensa um processo, iniciado nos anos 1950, de discussão e formulação de um projeto de ampla 
e profunda reforma do sistema público de saúde do país, numa mobilização de caráter nacional conhecida como "Movimento Sanitário”.

Do final dos anos 70 ao início dos anos 80 do século XX as organizações populares e as mobilizações em torno da temática da saúde procuravam articular os contextos local e nacional, conjugando a luta relacionada com os problemas e questões específicas do bairro e do município à luta contra a ditadura e pelo restabelecimento da democracia.

Em meados dos anos 1980, apesar da derrota da ampla mobilização nacional pelo restabelecimento das eleições diretas para presidente da República e pelo fim da ditadura militar, o país inicia seu processo de redemocratização com a eleição, no Congresso Nacional, de seu primeiro presidente civil, depois de 20 anos de ditadura., Isso dá início à discussão das reformas e mudanças necessárias ao pleno restabelecimento das instituições democráticas e ao aprofundamento da democracia.

Muitos municípios brasileiros, mesmo antes do fim da ditadura, haviam passado por tentativas de gestão mais democráticas, promovidas pelo então partido de oposição, o MDB, com a implantação de experiências embrionárias de orçamento participativo (nos municípios de Lages, em Santa Catarina, e Vila Velha, no Espírito Santo) e de um modelo médico-assistencial voltado para a atenção primária, privilegiando as ações preventivas e algum nível de participação popular (conselhos chegaram a ser implantados em algumas unidades de saúde em municípios dos estados de São Paulo e Paraná).

Em Campinas, nas gestões do MDB/PMDB, o enfrentamento político entre os dois modelos e projetos de atenção à saúde em disputa no país ${ }^{4}$ e contra o autoritarismo das relações entre prefeitura e Movimento Popular de Saúde ocorria em duas frentes:

\footnotetext{
${ }^{4}$ O primeiro, de caráter liberal e privatista, vinculado às contribuições previdenciárias, privilegiando o tratamento hospitalar, e o segundo, de caráter público, de valorização das ações preventivas, unificado, descentralizado e participativo.
} 
dentro da própria prefeitura, entre secretário, funcionários da rede municipal de saúde ${ }^{5}$ e prefeito, e entre MOPS e administração.

A forte aliança existente entre MOPS e profissionais da rede, concretizada, principalmente, através das assessorias prestadas por estes profissionais ao movimento (realização de debates, seminários, denúncia de situações desconhecidas pela população, informação e elaboração de boletins informativos), contribuiu para o seu fortalecimento e para a qualificação dos enfrentamentos com a administração municipal. O movimento contava com o suporte de dados e informações fornecidas por estes profissionais, com o apoio para a divulgação e realização de eventos e com o processo de reflexão e crítica às posturas políticas e propostas apresentadas pela prefeitura para a política municipal de saúde.

Entre os anos de 1979 a 1981 o embate entre secretário de saúde, funcionários da rede e Executivo municipal foi importante para o aprofundamento da relação entre Movimento Popular de Saúde e seus profissionais. A secretaria de Saúde instituiu um modelo participativo de relacionamento com seus funcionários, em que os mesmos passaram a tomar parte das decisões referentes ao processo de trabalho na secretaria e nas unidades de saúde, por meio de comissões de representantes.

As comissões de representantes dos funcionários da rede foram um importante instrumento para a viabilização de outro modelo de saúde, em que a participação popular se colocava como suporte fundamental.

Esta era uma estrutura fundamental no sentido de viabilizar concretamente as propostas expressas e absorvidas a nível do Movimento Popular. Constituía-se no suporte à legitimação das pressões populares junto ao aparelho de Estado no qual se sustentavam as práticas que

\footnotetext{
Como resultado das articulações políticas realizadas para a disputa eleitoral, a distribuição dos cargos de secretários municipais propiciava, por vezes, que a ocupação de determinadas secretarias fosse realizada por políticos com posições divergentes e até contrárias às do chefe do Executivo. Tal foi o caso da gestão do prefeito Chico Amaral, no final dos anos 1970, em que sérios conflitos entre prefeito e secretário de saúde, quanto à condução da política municipal de saúde, mas principalmente quanto à relação com funcionários e população, redundaram na demissão do secretário em maio de 1981 (SMEKE, 1989, p. 116).
} 
buscavam explorar as brechas abertas pelas contradições institucionais (SMEKE, 1989, p. 193).

Esta experiência provocou o acirramento da disputa política travada no interior da prefeitura. Tratava-se de uma prática democrática de relacionamento entre secretário, funcionários e população em nada similar às práticas de outros órgãos da prefeitura e do chefe do Executivo municipal. A existência desta contradição no interior da própria prefeitura culminou com a demissão, em 1980, dos funcionários cujas ações revelavam maior comprometimento com o movimento popular. Embora esta situação tenha provocado um processo longo de disputa entre funcionários, prefeitura e Movimento Popular de Saúde e no interior do próprio MOPS e da Assembléia do Povo, a disputa se resolveu com o encerramento da experiência e a demissão do secretário de saúde. ${ }^{6}$

A solução encontrada não foi suficiente, entretanto, para evitar o aprofundamento da aliança entre profissionais e Movimento Popular de Saúde, o adensamento e a defesa no interior deste movimento de um novo modelo de atenção à saúde, voltado para as reais necessidades da população e participativo. Como sinais desta relação podemos citar a luta empreendida contra a epidemia de esquistossomose vivida pela população pobre de Campinas de 1979 a 1981, em que as denúncias, pesquisas e dados fornecidos pelos profissionais foram fundamentais para impulsionar e sustentar o movimento, a criação do "Sapo" (boletim informativo do MOPS chamado "Saúde Popular"), em 1986, na região Cura D'Ars e a realização anual, a partir de novembro de 1987, dos seminários “Saúde e Participação Popular”.

Os seminários "Saúde e Participação Popular" foram espaços privilegiados para a aglutinação das comissões populares

\footnotetext{
O trabalho da professora doutora Elizabeth de Leone Monteiro Smeke "Saúde e Democracia, experiência de gestão popular: um estudo de caso", de 1989, trata com detalhes esta experiência e alguns dos seus desdobramentos. Para os propósitos deste trabalho, o importante é ressaltar o seu papel no estreitamento das relações entre profissionais de saúde e MOPS e no fortalecimento do próprio MOPS na cidade.
} 
de saúde existentes em toda a cidade e para a reflexão da conjuntura e situação da saúde no município e no país.

Outro espaço criado para aglutinação do movimento e definição de suas posições e bandeiras foram as plenárias do Movimento Popular de Saúde. As plenárias foram usadas, e ainda têm sido usadas, com mais freqüência para a eleição dos representantes do MOPS no Conselho Municipal de Saúde.

Uma aliança fundamental à continuidade do movimento nos anos 1980 foi a realizada com o movimento sindical, com as oposições sindicais que se tornaram, posteriormente, direções de importantes sindicatos da cidade (sindicatos dos metalúrgicos, da construção civil, dos condutores, dos vidreiros, petroleiros, bancários, eletricitários, trabalhadores da SANASA, etc.). A parceria entre MOPS e movimento sindical foi fundamental para a viabilização da própria existência do MOPS. Os sindicatos sempre foram parceiros e viabilizaram os recursos necessários à realização de reuniões, seminários, jornais, panfletos, relatórios, caminhões de som e mesmo recursos simples de comunicação como telefonemas e cartas.

Neste período, as lideranças que mais se destacaram em todo o processo eram vinculadas às CEBs da região Cura D'Ars, Vila Costa e Silva, Vila Ipê e Jardim Nova Europa, onde as lutas pela construção de centros de saúde foram mais acirradas e também mais bem sucedidas. O enfrentamento com a prefeitura, no Jardim Santa Odila, na região Cura D'Ars, pela construção do Centro de Saúde se deu por um período de quase dez anos. Em 1988, como a obra foi finalizada, mas não entregue, a população fez um ato público inaugurando o novo centro com um culto ecumênico, a presença de diversos outros movimentos sociais e a pintura dos muros do centro de saúde com a história da luta de seus moradores e dos movimentos sociais da cidade. O protesto gerou grande desconforto para o secretário de saúde e o prefeito, que cobriram com tinta cinza os muros coloridos e realizaram a inauguração oficial. 
Esta experiência pode ser considerada uma síntese dos embates entre Movimento Popular de Saúde e administração no período.

No desenvolvimento destas tensões e disputas, a fundação do Partido dos Trabalhadores na cidade, reunindo lideranças do movimento sindical e popular, significou o aparecimento das primeiras diferenciações no interior dos movimentos sociais, principalmente quanto à relação com o Estado.

Para algumas lideranças, o embate político dentro dos moldes tradicionais, com a constituição de um partido e a disputa eleitoral, poderia significar o fim da autenticidade e da autonomia adquirida pelo movimento.

O que aconteceu a partir de fins dos anos 1980, com o processo constituinte, foi um privilegiamento da construção das instituições democráticas e de todo um corpo legislativo e institucional que pudesse assegurar os direitos constitucionais recém adquiridos.

$\mathrm{Na}$ saúde esta era uma tendência desde o início dos anos 1980 nos primeiros governos estaduais de oposição e mesmo nos ministérios da Saúde e da Previdência Social. Militantes do Movimento Sanitário (profissionais de saúde, principalmente), vinculados aos partidos clandestinos abrigados no PMDB (em particular o antigo Partido Comunista Brasileiro/PCB), deram início ao processo de mudança na legislação e nas instituições responsáveis pela implantação da política de saúde, com a criação das AIS (Ações Integradas de Saúde, envolvendo municípios, estados e governo federal) e do SUDS (Sistema Unificado e Descentralizado de Saúde).

Estes processos expressavam a existência no interior do movimento pela reforma sanitária de duas grandes correntes quanto à concepção de Estado e às estratégias a serem usadas 
na luta política. A de maior influência, principalmente nos anos 1970 e 1980, vinculada ao Partido Comunista Brasileiro, compreendia o processo de transformação social a partir do interior do próprio aparato de Estado por meio do desmonte de sua lógica (de sustentação dos negócios privados), introduzindo uma lógica de priorização do público (compreendido como estatal) e de privilegiamento dos interesses das classes dominadas nas ações dos agentes estatais. A segunda corrente, vinculada aos emergentes movimentos populares e ao recém-criado Partido dos Trabalhadores, defendia o fortalecimento da sociedade civil organizada e o privilegiamento da participação popular, por meio do ingresso das forças populares na arena política, não apenas expressando seus interesses e demandas, mas participando do processo decisório.

Durante os anos 1980 e início dos anos 1990, a construção da legislação e a formalização dos direitos adquiridos e de mecanismos de participação popular foram as principais preocupações do movimento pela reforma sanitária - o que contribuiu para o fortalecimento da vertente do movimento vinculada ao privilegiamento das ações políticas no interior do aparato de Estado, uma vez que, para a aprovação da lei orgânica da saúde e, posteriormente, para assegurar a participação popular nas instâncias decisórias do sistema ${ }^{7}$, foi necessário um intenso processo de articulação, mobilização e negociação junto ao Executivo e ao Congresso Nacional.

Esta ênfase na construção do aparato legislativo e institucional considerado necessário para garantir a saúde como direito de todos e dever do Estado, mobilizou as comissões e movimentos populares de saúde em todo o país para assegurar que também as leis orgânicas municipais garantissem direitos e introduzissem mecanismos legais de participação popular.

O então presidente da República, Fernando Collor de Mello, vetou os artigos da lei orgânica
que asseguravam a participação popular, por meio de conselhos, na formulação e fiscalização da
política de saúde nos três níveis de governo. Para garantir a participação popular foi necessário
mobilizar a sociedade e negociar junto ao Executivo e ao Congresso Nacional uma nova lei com
os artigos que tratavam deste tema e que haviam sido vetados pelo presidente (SILVA, 2001). 
Nesta direção, o MOPS-Campinas teve papel destacado tanto no processo de discussão da lei orgânica do município quanto na elaboração do aparato legislativo definidor das funções e características do Conselho Municipal de Saúde da cidade.

\section{O MOPS e a construção do Conselho Municipal de Saúde no final dos anos 1980}

Ao incorporar direitos sociais e inserir a participação da sociedade como diretriz política a ser seguida na formulação e fiscalização de políticas públicas, a Constituição brasileira de 1988 representou uma vitória das forças sociais de caráter democratizante. Entretanto, a definição de mecanismos para viabilização desta diretriz foi objeto de disputa ao longo dos anos 1990 no processo de elaboração das leis orgânicas de cada área das políticas públicas e das leis orgânicas municipais.

O movimento pela reforma sanitária formulou todo um conjunto de propostas, ao longo de décadas de movimento, para mudanças no sistema de saúde, para construção de um sistema público, de caráter universal, equitativo, descentralizado e participativo. Dois anos após a promulgação da nova Constituição a lei orgânica da saúde foi aprovada, num processo no qual se envolveram os movimentos populares de saúde do país inteiro e em que foram realizadas muitas negociações junto ao Legislativo.

Após os vetos presidenciais aos artigos da lei orgânica da saúde que estabeleciam os mecanismos viabilizadores da participação da sociedade, uma frente política, que reuniu movimento popular, trabalhadores e parlamentares, articulou a elaboração de um novo projeto de lei assegurando a inclusão de mecanismos de participação da sociedade no Sistema Único de Saúde (SUS) nos três níveis de governo (SILVA, 2001).

Em Campinas, desde a realização do primeiro seminário "Saúde e Participação Popular", o MOPS tornou a discussão de 
um novo modelo de atenção à saúde uma preocupação nuclear, chegando a montar um programa de saúde para o município e entregá-lo à administração municipal.

Dentro deste programa, entre as propostas, além da criação do Conselho Municipal de Saúde, estava a instauração de conselhos locais nas unidades de saúde do município. Militantes do MOPS viajaram pelo país para conhecer as experiências de Conselhos Locais em andamento. Entretanto, a experiência balizadora das propostas do MOPS foi a da zona leste de São Paulo. O Movimento Popular de Saúde da zona leste formulou uma proposta de lei para criação de Conselhos Locais e regulamentação dos existentes. Esta proposta foi estudada pelos militantes do MOPS, aperfeiçoada e apresentada a um vereador do Partido dos Trabalhadores, cuja militância começou nas comissões populares de saúde e no MOPS, e este a apresentou à câmara municipal.

Em 1988, com a vitória de uma frente de esquerda, hegemonizada pelo Partido dos Trabalhadores, para a administração municipal em Campinas, militantes do movimento pela reforma sanitária assumiram a secretaria de Saúde e passaram a discutir junto ao Movimento Popular de Saúde e aos trabalhadores uma proposta de legislação e de regimento interno para criação e regulamentação do Conselho Municipal de Saúde.

A criação deste Conselho no contexto das propostas feitas pelo MOPS para mudanças na política municipal de saúde estava em consonância com as resoluções aprovadas na $8^{a}$ Conferência Nacional de Saúde. Ou seja, a discussão envolvendo a criação do Conselho Municipal de Saúde foi balizada pelo conjunto de

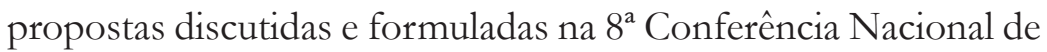
Saúde. Entretanto, ela foi, também, envolvida pelos temores das conseqüências que a criação deste espaço pudesse acarretar para o movimento, dificultando a manutenção da independência em relação aos políticos e aos poderes públicos e de sua autonomia de pensamento e ação. 
Há, neste sentido, um vislumbre, por parte destas lideranças, da dinâmica diferenciada de ação no espaço político representado pelos conselhos. Observa-se uma tensão entre ocupar este espaço, negociar e ser co-responsável pelos resultados destas negociações, assumindo as exigências requeridas pela representação e, ao mesmo tempo, manter a capacidade de crítica e de enfrentamento dos poderes públicos.

A preocupação das principais lideranças do MOPS era tanto garantir um espaço de intervenção e interlocução com os poderes públicos e demais atores envolvidos com a política de saúde quanto preservar sua capacidade de discutir, formular e lutar por mudanças na política de saúde em consonância com os interesses da população usuária, de maneira autônoma.

Para tanto, suas principais lideranças evitaram, por dois anos, elegerem-se como representantes dos usuários no Conselho Municipal de Saúde. O que sustentava esta posição? Estas lideranças acreditavam que um compromisso com o Conselho poderia prejudicar a atuação dentro do movimento, sua capacidade de organização e mobilização.

Sustentar esta posição por muito mais tempo, entretanto, não foi possível. No espaço de dois anos, os representantes do MOPS no Conselho foram trocados três vezes. Os primeiros a serem eleitos foram pessoas próximas ao movimento, mas não eram seus militantes, não tinham a prática do debate, da participação regular em discussões. Desistiram de seus cargos nos primeiros seis meses de funcionamento do conselho.

$\mathrm{Na}$ terceira troca, suas lideranças mais conhecidas foram eleitas para a suplência e, mais tarde, assumiram a titularidade. Há indicações de que os primeiros representantes do MOPS não tinham compromisso com o espaço e lhes faltava a prática da argumentação e negociação necessárias ao processo de discussão e decisão no conselho, habilidades comuns a suas lideranças, pois muitos foram preparados por organizações de capacitação de lideranças populares vinculadas a partidos e à igreja católica. 
$\mathrm{Na}$ primeira legislação regulamentadora do Conselho Municipal de Saúde ${ }^{8}$, a composição tripartite definida determinava que o Conselho seria composto por usuários, prestadores de serviços, setores governamentais e universidades. Dentre os usuários, o MOPS e o movimento sindical eram os seus representantes majoritários, com seis membros para cada movimento.

A legislação, debatida por administração, movimento popular e trabalhadores, reconhecia a legitimidade destes movimentos como representação majoritária dos usuários do sistema de saúde municipal.

Neste momento, esta composição refletia o conjunto de forças articuladas na sociedade civil e sua capacidade de se colocar como sujeito político no debate no qual estiveram envolvidos administração municipal e legislativo.

É importante ressaltar que a vitória, em 1988, para a administração municipal de uma frente de esquerda sinalizou a existência do compartilhamento de projetos políticos democratizantes entre organizações da sociedade civil e partidos políticos situados à esquerda do espectro político na cidade.

Ao longo do processo de funcionamento do Conselho esta articulação, e mesmo o compartilhamento de projetos, sofreria mudanças, provocando alterações tanto na composição do Conselho quanto na representação dos usuários.

Uma alteração significativa neste sentido foi a valorização pelo MOPS da criação e fortalecimento dos Conselhos Locais nas unidades de saúde do município.

Além do envolvimento do MOPS para aprovação da lei que instituiu os Conselhos Locais, houve um grande empenho na divulgação da lei (jornais do movimento e cartilhas) e na capacitação dos futuros conselheiros (seminários e cursos).

8 Lei $\mathrm{N}^{\circ}$ 6.369, de 27 de dezembro de 1990. 


\section{A especificidade dos Conselhos Locais de Saúde}

Os Conselhos Locais de Saúde foram oficializados com uma legislação específica em junho de 1991, após apresentação pelo Movimento Popular de Saúde de uma proposta de lei à Câmara de Vereadores e grande mobilização para aprová-la. Sua elaboração contou com a participação das Comissões Populares de Saúde do município, sindicatos e outros movimentos sociais. E embora a administração também defendesse sua criação, o caráter da proposta apresentava diferenciações importantes em relação à proposta defendida pelo MOPS.

A administração pensava, inicialmente, em criar comissões de caráter técnico e administrativo, sem grande ênfase em seu aspecto político e decisório. Para o MOPS, tratava-se de criar Conselhos com caráter deliberativo, espaços nos quais os problemas de saúde do bairro e da região, bem como o desenvolvimento local da política municipal de saúde, pudessem ser discutidos pelos usuários do sistema.

As negociações realizadas para aprovação do projeto de lei instituindo os Conselhos Locais nas unidades de saúde resultaram em sua definição como instância de estabelecimento, controle e avaliação da política de saúde na área de abrangência da unidade e cuja composição também seria tripartite, com gestores, trabalhadores e usuários distribuídos na seguinte proporção: $25 \%$ de gestores, 25\% de trabalhadores da saúde e 50\% de usuários. A mesma proporção seria observada no Conselho Municipal de Saúde.

Os jornais do MOPS demonstram o quanto o movimento valorizava a constituição destes novos espaços.

Não queremos só o Centro. Queremos também participar das discussões, decisões e ajudar a gerenciar os seus serviços. Queremos saber porque faltam instrumentos de trabalho no posto, porque falta médico, enfermeiros e porque eles faltam. 
Afinal, somos capazes de zelar pela saúde que é nossa. Só não nos davam oportunidade. Hoje, com a nova lei orgânica do município conseguimos em parte garantir esse direito nosso e poderemos participar do Conselho Local de Saúde (CLS) e do Conselho Municipal de Saúde (SAPO, 1990).

A constituição dos Conselhos Locais se coadunava com o próprio modelo de organização do movimento, Comissões Populares de Saúde nos bairros, proporcionando ao MOPS um espaço de interlocução e de intervenção política muito mais próximo da realidade dos moradores.

Inicialmente os Conselhos proporcionaram ao MOPS este espaço político, mas sua expansão por toda a rede de unidades do município resultou na geração de alguns problemas para a administração e para o próprio movimento.

Para a administração, os maiores desconfortos foram as dificuldades de relacionamento entre os representantes dos usuários nos conselhos, coordenadores, chefias e o corpo de funcionários. Alguns representantes começaram a agir acreditando que, por serem conselheiros, teriam privilégios no atendimento da unidade, para eles mesmos e para seus familiares, bem como poderiam interferir no desenvolvimento do trabalho realizado pelos funcionários. Tal fato acabou por gerar grandes conflitos entre funcionários e conselheiros e a ocupar o espaço de discussão das reuniões do Conselho Local.

Para o MOPS, os problemas enfrentados se colocaram em duas frentes. A primeira delas, a dos conflitos entre conselheiros, representantes dos usuários, coordenadores, chefias e funcionários, obrigou o MOPS a intervir trabalhando como mediador nos conflitos e desenvolvendo um processo de capacitação dos conselheiros, para que estes pudessem entender a natureza de seu papel dentro do Conselho e na unidade. A segunda foi um esvaziamento das Comissões Populares de Saúde existentes nos bairros. Primeiro porque algumas lideranças se tornaram representantes dos usuários e passaram a ter um papel no 
controle e fiscalização dos serviços prestados pela unidade, sobrecarregando-a de atividades e reduzindo sua disponibilidade para o movimento. Segundo porque os conselheiros passaram a ser os interlocutores da população não apenas junto à unidade, mas também junto à administração, reduzindo a importância das Comissões Populares de Saúde como espaço de crítica e articulação de moradores e usuários.

A redução do papel político das Comissões Populares de Saúde talvez tenha sido a mais séria conseqüência para a organização e permanência do MOPS. Na medida em que as Comissões Populares de Saúde foram perdendo sua importância e os Conselhos Locais, mas, principalmente, os conselheiros, tornaram-se uma referência para a população apresentar críticas, queixas e demandas, estes espaços tornaram-se um suporte para o próprio MOPS na sustentação de suas relações com a população. O movimento foi perdendo sua capacidade de articulação e sustentação na organização autônoma das Comissões Populares de Saúde nos bairros e tornou-se quase dependente do espaço de articulação e debate proporcionado pelos Conselhos Locais.

Este processo desenvolveu-se ao longo dos anos 1990 e produziu um certo descolamento entre o colegiado que compõe a coordenação municipal do MOPS e suas bases de sustentação nos bairros. A coordenação do MOPS passou a trabalhar na realização das eleições para os conselheiros locais e a ter este momento como um instante privilegiado para a articulação, mobilização e organização das lutas.

Os Conselhos Locais de Saúde são responsáveis pelo controle e fiscalização da política municipal de saúde em nível local e regional. Estão mais próximos, portanto, dos problemas sofridos pela população em seu cotidiano. Suas reuniões normalmente acontecem no próprio posto ou centro de saúde e seus membros são pessoas com as quais os usuários lidam sempre que se dirigem às unidades de saúde do município. 
Estas circunstâncias contribuíram para que se tornassem importantes espaços de expressão de insatisfação dos usuários. Após a realização das eleições, cartazes com os nomes dos conselheiros eleitos, telefones e endereços ficam, em caráter permanente, fixados no quadro de avisos da unidade. Durante o processo eleitoral há um esforço do MOPS para que a população tome conhecimento das eleições e dos candidatos. Estes, depois de eleitos, são abordados pelos moradores e recebem reclamações, críticas, por meio de telefonemas, nas ruas, no supermercado, na igreja, onde quer que se encontrem. Estes conselheiros também são procurados pelos representantes dos usuários no Conselho Municipal de Saúde para o repasse de informações e mesmo para a mobilização dos usuários para o debate de temas e enfrentamento de problemas.

A institucionalização dos Conselhos Locais de Saúde foi produto de uma reivindicação do MOPS e atendeu a uma demanda por participação em nível local. Mas, a conquista deste espaço, com regras bem definidas de funcionamento, esvaziou os espaços autônomos de participação (Comissões Populares de Saúde) e dificultou sua criação onde estes não existiam. Suas lideranças passaram a ter dificuldade para desempenhar o papel de representantes dos usuários neste espaço e, ao mesmo tempo, informar, articular, reunir, enfim, organizar a população para o debate e a tomada de posições.

Todo o processo de institucionalização de mecanismos de participação no interior dos órgãos responsáveis pela política de saúde nos três níveis governamentais tem impulsionado uma expansão de processos representativos, principalmente na radicalização da autonomia entre representantes e representados, ao nível das relações entre lideranças de movimentos sociais e suas bases societárias.

A consolidação e a viabilização da lei orgânica da saúde redirecionaram o eixo da luta política. Não se trata mais de lutar para garantir o reconhecimento de direitos, assegurar sua configuração legal, mas para que se viabilizem, no cotidiano de 
funcionamento do sistema, o que explica a importância adquirida pelos Conselhos Locais de Saúde. $\mathrm{Na}$ medida em que estes Conselhos são as instâncias responsáveis por controlar e fiscalizar o desenvolvimento da política de saúde no cotidiano das unidades, são os responsáveis por assegurar a operação do direito.

O reconhecimento do direito é o patamar a partir do qual os representantes dos usuários irão pautar sua ação política nos espaços dos Conselhos. A prática do enfrentamento direto, necessária ao reconhecimento de uma demanda e do sujeito político que reivindica sua inscrição na sociedade que o exclui, parece deslocada.

Esta constitui uma das explicações para o fortalecimento da lógica representativa no espaço de participação proporcionado pelos Conselhos. Uma vez que os sujeitos políticos e seus direitos foram reconhecidos, trata-se de consolidar este reconhecimento em termos da vida cotidiana do sujeito que o demandou. A representação neste contexto se faz a partir de algo já tomado como comum. Representa-se um sujeito e um direito já reconhecidos.

Que o povo seja diferente de si mesmo não é, para a política, um escândalo que se precise denunciar. É a condição primeira de seu exercício. Há política desde que exista a esfera de aparência de um sujeito povo cuja propriedade consiste em ser diferente de si mesmo. Logo, do ponto de vista político, as inscrições da igualdade que figuram nas declarações dos direitos do homem ou nos preâmbulos dos códigos e das constituições, as que materializam tal ou qual instituição ou que estão gravadas no frontão de seus edifícios, não são "formas" desmentidas por seu conteúdo ou "aparências" feitas para esconder a realidade. São um modo efetivo do aparecer do povo, o mínimo de igualdade que se inscreve no campo da experiência comum. O problema não é acusar a diferença entre essa igualdade existente e tudo o que a desmente. Não se trata de desmentir a aparência, mas, ao contrário, de confirmá-la. Lá onde está inscrito a parcela dos semparcela, por frágeis e fugazes que sejam essas inscrições, é criada uma esfera do aparecer da demos, existe um elemento do kratos, do poder do povo. O problema está em ampliar a esfera desse aparecer, em aumentar esse poder (RANCIËRE, 1996, p. 94). 
Em 1998, após lutas e negociações dentro do Conselho Municipal de Saúde de Campinas, os usuários conquistaram o direito a também ocupar a presidência deste órgão. O que confirma o reconhecimento deste sujeito e do seu direito.

\section{O MOPS-Campinas e a produção da política municipal de saúde}

A agenda de debates do Conselho Municipal de Saúde de Campinas tem sido dominada pela discussão dos convênios e contratos com prestadores de serviços para atendimento das necessidades do SUS municipal. A discussão de temas polêmicos e de programas que coloquem em xeque ou reiterem e consolidem os princípios da equidade e universalidade do Sistema Único de Saúde é menos freqüente e segue um percurso bem mais demorado.

Observamos que o MOPS, em articulação com os profissionais de saúde, travou, ao longo de dez anos, disputas com os gestores da saúde nos três níveis de governo pela implantação de duas grandes mudanças na política municipal de saúde ${ }^{9}$. A primeira delas refere-se às mudanças no tratamento dispensado aos portadores de sofrimento mental e, a segunda, à melhoria dos serviços de assistência médica emergencial.

A luta por uma política municipal de saúde mental que substituísse as internações, o isolamento e o tratamento medicamentoso dos portadores de sofrimento mental foi travada em conjunto com os profissionais de saúde da área e envolveu vários municípios da região. $\mathrm{O}$ debate em torno do tema no município se introduz de maneira mais consistente a partir de 1991, após a realização da $2^{a}$ Conferência Municipal de Saúde em que reivindicações por mudanças nos serviços oferecidos pelo município aos portadores de sofrimento mental aparecem pela primeira vez -( CONFERÊNCIAS MUNICIPAIS DE SAÚDE DE CAMPINAS, 1990-2003).

Estas políticas foram escolhidas em função de representarem mudanças bastante profundas nos serviços prestados pelo SUS municipal. 
Após a introdução do tema nesta Conferência, ele passou a ser objeto de debate no Conselho Municipal de Saúde da cidade e o próprio Conselho passou a organizar debates e Conferências no município e na região com este objetivo. Este debate, em Campinas, foi simultâneo à organização da luta anti-manicomial entre os profissionais de saúde em todo o país, visando uma mudança profunda no atendimento prestado pelos serviços de saúde mental aos seus pacientes. A mudança mais significativa a partir desta discussão no município de Campinas foi representada pela substituição das internações psiquiátricas por Centros de Apoio Psicossocial, em que os portadores de sofrimento mental passaram a receber, em regime de liberdade, um tratamento integral, que incluía a terapia medicamentosa, psicológica e ocupacional.

Desde a criação dos primeiros CAPS, o Movimento Popular de Saúde e os profissionais engajados na luta anti-manicomial têm, em todas as Conferências Municipais de Saúde, reivindicado o aumento no número de CAPS e de outras ações, objetivando a desinternação dos portadores de sofrimento mental (Hospital Dia, Lar Terapêutico, Oficinas de Trabalho, Centros de Convivência). É significativo que este movimento, articulando profissionais de saúde e MOPS, tenha desde o início dos anos 1990 não só introduzido o tema no debate realizado no Conselho e nas Conferências, como conquistado mudanças substantivas na política municipal de saúde mental.

Neste sentido, observou-se em Campinas uma confluência virtuosa entre as reivindicações do Movimento Popular de Saúde e dos profissionais da área, capaz de introduzir o tema na agenda pública e produzir ações no sentido de assegurar o debate e a produção de medidas que atendessem às mudanças propostas.

O processamento destas mudanças não aconteceu de maneira rápida e o principal instrumento usado neste trabalho para avaliar este processo foi a observação das reivindicações em torno do tema nas Conferências Municipais de Saúde. Notamos que na $5^{\mathrm{a}}$ conferência, realizada em 2000 , ainda aparece a construção de 
CAPS, Oficinas de Trabalho e Lares Abrigo para o atendimento aos portadores de sofrimento mental, mas não como prioridade. A prioridade, a partir desta Conferência, passa a ser aumentar o número de profissionais nos equipamentos existentes, capacitar as equipes de trabalho de todas as unidades de saúde para o acolhimento dos pacientes em sofrimento mental, garantir atendimento de urgência psiquiátrica nos prontos-socorros do SUS e, o mais significativo, "Manter a qualidade de atendimento de todos os equipamentos de saúde mental existentes" (Relatório

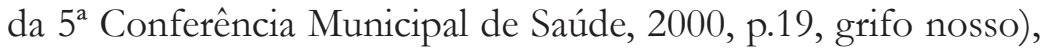
sinalizando para o quanto a mudança de direção reivindicada na política municipal de saúde mental no início dos anos 1990 parecia consistentemente consolidada.

Esta sinalização parece ainda mais firme se considerarmos que as deliberações apresentadas nos relatórios finais das Conferências Municipais de Saúde são aprovadas por plenárias reunindo os representantes de todos os segmentos envolvidos com o tema (usuários, trabalhadores do setor e gestores).

A mudança na política municipal de atendimento de urgência também passou por percurso semelhante. A primeira aparição do

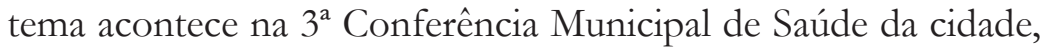
realizada em 1994, em que se reivindica a "Implementação de um Projeto de Transporte de Urgência e Emergência da Secretaria Municipal de Saúde" -( CONFERÊNCIAS MUNICIPAIS DE SAÚDE DE CAMPINAS, 1990-2003). A partir daí, a criação deste projeto passa ser discutida no Conselho Municipal de Saúde da cidade. Em junho de 1996 foi criado pela Secretaria Municipal de Saúde o "Serviço de Atendimento Médico de Urgência/SAMU", cujo nome mudou posteriormente para "Serviço de Atendimento Móvel de Urgência”, mantendo-se a sigla.

No relatório da $4^{\mathrm{a}}$ Conferência Municipal de Saúde, realizada em 1997, não há nenhuma referência ao serviço. Já no relatório da $5^{\text {a }}$ conferência, realizada em 2000, se reivindica que o SAMU seja legitimado como regulador do atendimento de urgência e que haja uma cobertura regionalizada para o serviço. A cobertura 
regionalizada e descentralizada dos serviços do SAMU tornou-se, a partir desta Conferência, a principal preocupação dos usuários e do MOPS, sendo freqüentemente pautada nas reuniões do Conselho Municipal de Saúde. As principais reivindicações passaram a girar em torno da manutenção, renovação e ampliação da frota de viaturas do SAMU e da descentralização dos serviços.

O principal problema para a implantação de um serviço descentralizado, em que as bases do SAMU estivessem junto aos distritos de saúde diminuindo a distância e o tempo necessário à realização do atendimento, era exatamente o pequeno número de viaturas da frota.

Uma análise das atas das reuniões do Conselho Municipal de Saúde mostrou que o longo período de espera pela chegada das viaturas do programa na periferia da cidade era uma queixa freqüente dos usuários e que a descentralização era apontada como a melhor solução.

Apenas em 2004 esta solução começou a ser implementada pelo poder público municipal. A partir deste ano, a melhoria e a expansão dos serviços de emergência nas grandes cidades brasileiras foram priorizadas pelo Ministério da Saúde. Pesa ainda neste processo o fato de a cidade ser administrada por uma frente de partidos hegemonizada pelo Partido dos Trabalhadores, que passou a ocupar o Executivo federal em 2003, e ter cedido alguns de seus quadros para o gestor federal, melhorando a comunicação entre os gestores. $\mathrm{O}$ fato é que, a partir deste ano, após assinatura de convênio com o Ministério da Saúde, a cidade passou a contar com uma frota maior e iniciou o processo de descentralização do programa.

\section{Considerações Finais}

$\mathrm{Na}$ discussão destes programas, observamos a existência de um processo de diferenciação nas discussões e disputas políticas travadas neste novo espaço de participação (os Conselhos) em 
relação à prática das ações diretas e de enfrentamento entre movimento popular e Estado, comum nos anos 1970 e 1980. Esta diferenciação torna o processo de entrada das demandas destes atores na agenda pública e a negociação de soluções bem mais demorados, embora menos sujeitos às interferências representadas pela mudança de gestores a cada eleição.

O Conselho e as Conferências Municipais de Saúde se transformaram em espaços nos quais as próprias demandas são formuladas, esvaziando os espaços de discussão autônomos representados pelos movimentos sociais e outras organizações da sociedade civil. E esta parece ser a principal mudança sofrida pelo Movimento Popular de Saúde de Campinas, bem como outros movimentos sociais em todo o país a partir da criação de arranjos participativos para formulação de políticas públicas. Houve uma redefinição do papel destes movimentos na cena pública, pois se transformaram em interlocutores políticos nestes arranjos, situação esta que ampliou suas tarefas. Além da tematização de problemas, da organização de demandas e articulação de indivíduos e grupos, tornaram-se co-responsáveis pela gestão da política, num cenário de recuo das redes de apoio constituídas por ONGs, igrejas e outros movimentos sociais e de dificuldades para agregar novos quadros, acrescentando um importante complicador às disputas travadas nestes espaços e ao processo decisório.

Embora se deva valorizar o quanto a participação do MOPS e do movimento de trabalhadores foi importante para que a política municipal de saúde sofresse alterações mais profundas, não deixa de ser relevante o longo período de maturação destas mudanças. Este fato evidenciou o quanto a negociação nestes arranjos (Conselhos, Conferências) passou a ocupar um espaço maior na vida do MOPS em detrimento de seu papel como mobilizador e articulador das demandas dos usuários.

A institucionalização de arranjos participativos assegurou o reconhecimento político de atores sociais coletivos como interlocutores nesta nova arena. Se, por um lado, a possibilidade de perda da capacidade de mobilização existe e tem sido um fato, por 
outro, os direitos conquistados e o reconhecimento de usuários, trabalhadores e movimentos sociais como interlocutores legítimos, têm proporcionado mais transparência ao processo decisório e consistência às decisões e políticas definidas nestes espaços.

Submetido em 20 de maio de 2009 e aceito para publicação em 11 de novembro de 2009

\section{Referências}

BRASIL. Lei n ${ }^{\circ}$ 6.369, de 27 de dezembro de 1990. Publicado no Diário Oficial da União em 28 de dezembro de 1990.

COHN, Amélia; ELIAS, Paulo E. Saúde no Brasil: políticas e organização de serviços. São Paulo: Cortez, CEDEC, 1996.

CONFERÊNCIA MUNICIPAL DE SAÚDE DE CAMPINAS, 19902003. Campinas. Relatórios Impressos, 34 p.

CONSELHO MUNICIPAL DE SAÚDE DE CAMPINAS. Atas de reuniões ordinárias e extraordinárias do Conselho Municipal de Saúde, realizadas no município de Campinas de 19 de setembro de 1990 a 26 de janeiro de 2005.

LOPES, Doraci Alves. Marginais da história? O movimento dos favelados da Assembléia do Povo. Campinas, São Paulo: Alínea, 1997.

MOVIMENTO POPULAR DE SAÚDE DE CAMPINAS. História do movimento popular de saúde. In: SEMINÁRIO SAÚDE E PARTICIPAÇÃO POPULAR, 2, 13 dez. 1987, Campinas.

RANCIÈRE, Jacques. O desentendimento: politica e filosofia. São Paulo: Ed. 34, 1996.

SILVA, Silvio Fernandes da. Municipalização da saúde e poder local: sujeitos, atores e politicas. São Paulo: HUCITEC, 2001.

SAPO: Boletim Informativo do Movimento Popular de Saúde de Campinas. Campinas, maio 1990.

SMEKE, Elizabeth de Leone Monteiro. Saúde e democracia, experiência de gestão popular: um estudo de caso. 1989, 556 p . Tese (Doutorado em Ciências Médicas) - Faculdade de Ciências Médicas, Universidade Estadual de Campinas, Campinas, 1989. 